\title{
Successful reconstruction of bilateral oral commissure fusion secondary to Stevens Johnson syndrome
}

\author{
Shadai Flores ${ }^{1}$, Dino Maglic ${ }^{2}$, Neal Moores ${ }^{2}$, Rayaad Hosein ${ }^{2}$, Faizi Siddiqi ${ }^{2}$, Barbu Gociman $^{2}$ \\ 1University of Utah School of Medicine, Salt Lake City, UT 84132, USA. \\ ${ }^{2}$ Plastic and Reconstructive Surgery, Department of Surgery, University of Utah Health Care, Salt Lake City, UT 84132, USA.
}

Correspondence to: Dr. Shadai Flores, University of Utah School of Medicine, Salt Lake City, UT 84132, USA.

E-mail: shadai.floresarce@hsc.utah.edu

How to cite this article: Flores S, Maglic D, Moores N, Hosein R, Siddiqi F, Gociman B. Successful reconstruction of bilateral oral commissure fusion secondary to Stevens Johnson syndrome. Plast Aesthet Res 2018;5:24. http://dx.doi.org/10.20517/2347-9264.2018.31

Received: 5 Jun 2018 First Decision: 13 Jul 2018 Revised: 18 Jul 2018 Accepted: 19 Jul 2018 Published: 27 Jul 2018

Science Editor: Raúl González-García Copy Editor: Jun-Yao Li Production Editor: Cai-Hong Wang

\begin{abstract}
Stevens Johnson syndrome (SIS) is a rare and often fatal hypersensitivity reaction commonly triggered by drugs which results in the uncontrolled destruction of keratinocytes with both cutaneous and mucosal involvement. Fusion of the oral commissures, although reported in burn victims, is a very uncommon complication of SJS. The successful reconstruction of oral commissures fusion using a modified commissuroplasty technique in a 19-year-old Hispanic female with severe microstomia secondary to SJS is presented here. Re-establishment of normal speech, oral intake, as well as aesthetic appearance were achieved.
\end{abstract}

Keywords: Steven Johnson syndrome, commissuroplasty, microstomia

\section{INTRODUCTION}

Stevens Johnson syndrome (SJS) is a type IV hypersensitivity reaction commonly triggered by drugs which results in the uncontrolled destruction of keratinocytes with both cutaneous and mucosal involvement. As a rare and often life-threatening disease, SJS has an annual incidence of approximately 1 to 6 cases per 1 million $^{[1]}$. Reportedly, ophthalmologic complications are among the most severe sequelae of SJS along with cutaneous and gastrointestinal manifestations ${ }^{[2]}$. Fusion of the oral commissures, although commonly reported in burn victims, is a very uncommon complication of SJS. Incomplete fusion of the oral commissures (bands connecting the lateral aspect of upper and lower lips but sparing the very corner of the mouth) in 

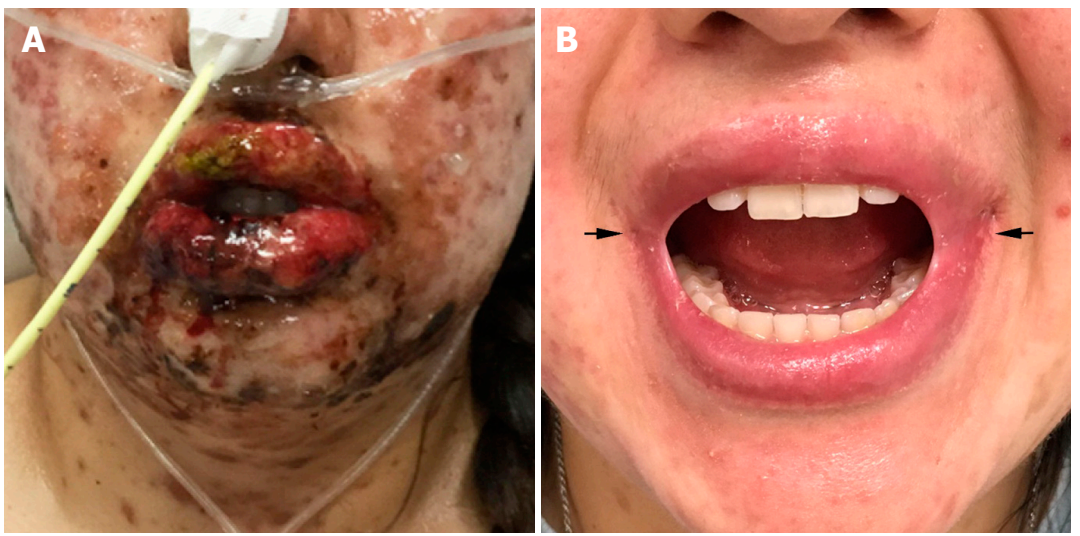

Figure 1. (A) Stevens Johnson syndrome manifested by generalized swelling and full thickness epidermal necrosis of the skin of face and the mucosa of the lips; (B) oral commissures fusion (arrows) resulting in impairment of normal speech, oral intake, as well as a compromised aesthetic appearance

the setting of SJS has only been reported four times with this being the first report of complete fusion ${ }^{[3-6]}$ (fusion of the upper to lower lip extending all the way to the corner of the mouth).

\section{CASE REPORT}

A 19-year-old Hispanic female was referred to the pediatric plastic surgery clinic for severe microstomia caused by bilateral oral commissure fusion post SJS. The SJS developed as a complication to oral sulfamethoxazole/trimethoprim used by the patient for the treatment of severe chronic acne vulgaris. This reaction to the medication resulted in generalized swelling and full thickness epidermal necrosis of the skin with involvement of face and the mucosa of the lips [Figure 1A]. Once the patient's condition stabilized re-epithelization of the affected areas commenced. During the re-epithelization process patient's oral commissures fused resulting in impairment of normal speech, oral intake, and compromised aesthetic appearance [Figure 1B]. Despite the fusion, the involved tissue remained relatively supple, in contrast to the usual thick and rigid scar associated with thermal or chemical burns).

We report here the successful functional and aesthetic reconstruction using a modified commissuroplasty technique. The procedure was performed under general anesthesia on outpatient basis. Incisions were performed at the level of the commissures in the shape of a 4-sided polygons with the long diagonal of $1.5 \mathrm{~cm}$ and the short diagonal of $1 \mathrm{~cm}$ [Figure 2A]. Full thickness excision of the scar present was performed preserving only the deep mucosal lining [Figure 2B]. The exposed mucosa was then divided in a Mercedes-sign pattern. This generated three separate mucosal flaps [Figure $2 \mathrm{C}$ ]. The lateral flap was used to resurface the corner of the mouth, while preventing overlapping sutures lines and re-fusion during the healing process. The superior flap was used to resurface the upper lip wound and the inferior flap to resurface the lower lip wound [Figure 2D]. The flaps were secured in place with interrupted deep dermal PDS sutures. The superficial lip mucosa was closed with a running 6-0 fast absorbing suture [Figure 2E].

The patient was discharged home in stable condition and had an uneventful postoperative course. Upon the postoperative visit at 6 weeks, the patient showed complete healing with a normalized oral opening, excellent function and an esthetically pleasant mouth contour [Figure 3].

\section{DISCUSSION}

Microstomia has various etiologies. It can be a congenital deformity or an oral manifestation of connective tissue disorders. Furthermore, it can be secondary to electrical, thermal and caustic injury, or the result of oncologic resection ${ }^{[7]}$. 


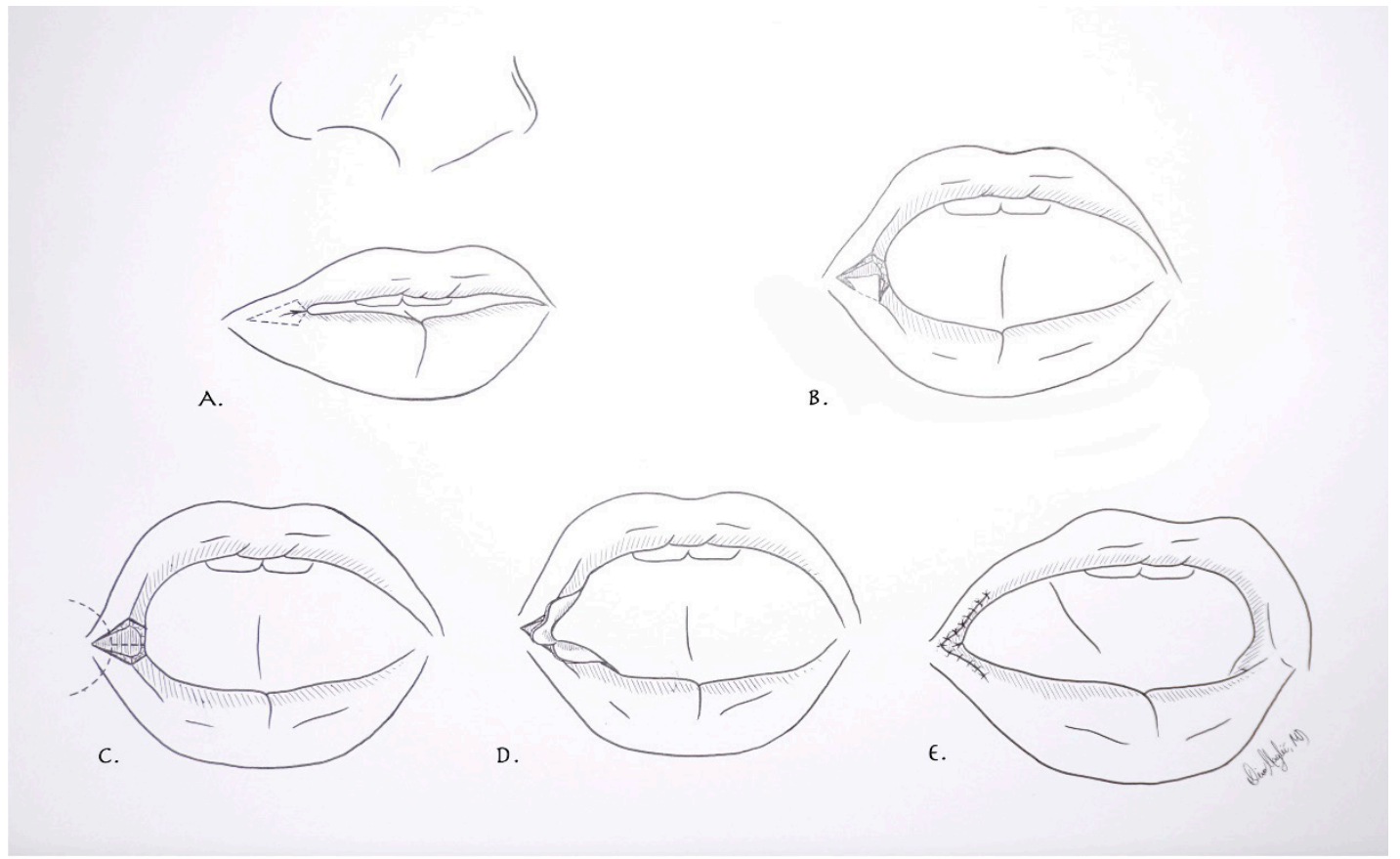

Figure 2. (A) Modified commissuroplasty technique. Incisions performed at the level of the commissures in the shape of a 4-sided polygons; (B) excision of the scar with preservation of the deep mucosal lining; (C) development of three separate mucosal flaps; (D) resurfacing of the corner of the mouth, upper and lower lip with individual flaps; (E) final closure with re-establishment of normal lip anatomy

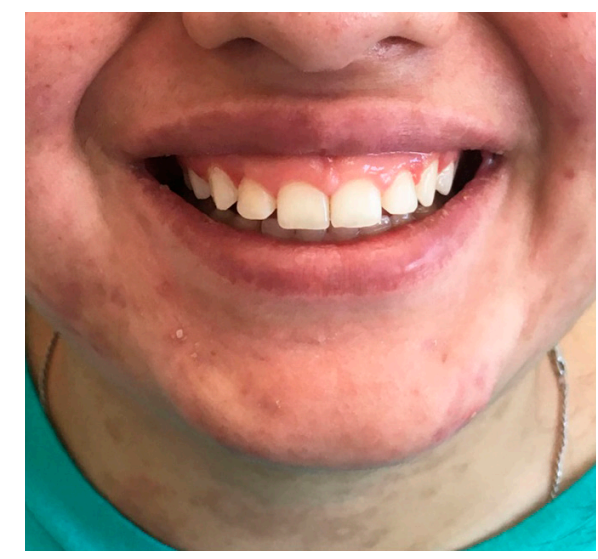

Figure 3. The 6-week postoperative image showing complete healing with a normalized oral opening and esthetically pleasant mouth contour

Microstomia is a challenging condition to treat. Its surgical reconstruction usually involves three steps: reestablishing the intended location of the commissure, excision of the existing scar and resurfacing of the resulting defect. While maintaining continuity of the orbicularis oris, the resurfacing can be achieved by primary closure, split or full thickness skin grafting, or local tissue re-arrangement ${ }^{[8,9]}$.

First employed by Dieffenbach in 1831, modified by Converse and later by Friedlander \& Millard, the Y-V advancement technique is a popular choice for treatment of commissural microstomia in burn patients ${ }^{[9,10]}$. The procedure described in the present report represents a slight modification of the technique. As the dry vermilion of the commissures was not affected by the scar tissue, it was not resected in our patient. The three mucosal flaps used to reconstruct each commissure were used to resurface the wet vermilion only. They were advanced and sutured to the intact dry vermilion at the level of the red line, replacing only similar tissue. 
In conclusion, although non-life threatening, microstomia can limit functionality and cause undue stress to the patients and their families. Using a modified commissuroplasty technique involving scar excision and mucosal advancement proved to be an effective treatment modality of microstomia secondary to SJS.

\section{DECLARATIONS}

\section{Authors' contributions}

Studied concept and designed the manuscript: Flores S, Gociman B

Drafted the manuscript: Flores S, Hosein R, Gociman B

Illustrated technique: Maglic D

Revised the manuscript: Gociman B

Supported clinical: Maglic D, Moores N, Hosein R, Siddiqi F, Gociman B

\section{Availability of data and materials}

Not applicable.

\section{Financial support and sponsorship}

None.

\section{Conflicts of interest}

The authors declare that there are no conflicts of interest.

\section{Ethical approval and consent to participate}

Ethics/Review board approval not applicable. The proper consent of the patient was taken for carrying out all the treatment and photographs.

\section{Consent for publication}

Patient's consent obtained.

\section{Copyright}

(c) The Author(s) 2018.

\section{REFERENCES}

1. Hötzenecker W, Prins C, French LE. Erythema Multiforme, Stevens-Johnson Syndrome, and Toxic Epidermal Necrolysis. In: Bolognia JL, Schaffer JV, Cerroni L, editors. Dermatology. Vol 1. Fourth Edition: Elsevier; 2018. p. 332-47.

2. Mockenhaupt M. The current understanding of Stevens-Johnson syndrome and toxic epidermal necrolysis. Expert Rev Clin Immunol 2011;7:803-13; quiz 814-5.

3. Sakamoto H, Nagashima T, Imai Y. Angular webbing associated with Stevens-Johnson syndrome. Int J Oral Maxillofac Surg 1993;22:118.

4. Marinho LH, Haj M, Pereira LF. Lip adhesion: an unusual complication of erythema multiforme. Oral Surg Oral Med Oral Pathol Oral Radiol Endod 1999;88:167-9.

5. Karincaoglu Y, Coskun BK, Seyhan M. An unusual complication of erythema multiforme and its treatment. Skinmed 2005;4:53-5.

6. Royan SJ. Lip adhesion: unusual complication of Stevens-Johnson syndrome. J Oral Maxillofac Surg 2010;68:901-3.

7. Microstomia. Available from: https://emedicine.medscape.com/article/878332-overview?src=refgatesrc1\#a5 [Last accessed on $23 \mathrm{Jul}$ 2018].

8. Kazanjian VH, Roopenian A. The treatment of lip deformities resulting from electric burns. Am J Surg 1954;88:884-90.

9. Zweifel CJ, Guggenheim M, Jandali AR, Altintas MA, Kunzi W, Giovanoli P. Management of microstomia in adult burn patients revisited. J Plast Reconstr Aesthet Surg 2010;63:e351-7.

10. Zak M, Means O, Cason B, Brooks R. Management of severe burn microstomia. Eplasty 2016;16:ic45. 